\title{
CONSUMO E LINGUAGENS DECORRENTES: IMPLICACCÕES PARA O CAMPO DA EDUCAÇÃO
}

\author{
Aloísio Ruscheinsky
}

RESUMO: As diferentes linguagens correspondem a circunstâncias históricas datadas e ao mesmo tempo possuem uma autonomia relativa dos respectivos contextos o que redobra de relevância uma abordagem a partir das ciências sociais. O artigo possui como objetivo destacar as linguagens decorrentes do consumo e suas implicações para o campo da educação, na perspectiva de consolidar uma educação ambiental emergente. Partimos do pressuposto teórico de que as diferentes linguagens são economicamente escoradas, socialmente referenciadas, politicamente circunstanciadas, culturalmente legitimadas. A exposição divide-se em quatro partes que destacam temáticas pertinentes à gênese e circunstâncias atuais da gestação de diferentes linguagens de uma cultura do consumo emergente em meio a uma sociedade com desigualdades persistentes e de impertinente degradação socioambiental.

Palavras-chave: Linguagens. Educação. Meio ambiente. Contradições. Teoria social.

* Doutor em Sociologia (USP/SP). Ex-docente do mestrado em Educação Ambiental (1997-2004). Pesquisador e docente do Programa de Pós-Graduação em Ciências Sociais (PPGCS), na UNISINOS/ RS, da linha de pesquisa sociedade e ambiente. Autor de vários livros, com interesse de pesquisa em desigualdades, políticas ambientais, educação, sustentabilidade. E-mail: aloisior@unisinos.br 


\section{INEQUALITIES AND CONSUMPTION: RECURRENT LANGUAGES AND IMPLICATIONS TO EDUCATIONAL FIELD}

ABSTRACT: Different languages correspond to dated historical circumstances and likewise, there is relative autonomy contexts relevance respectively to intensify an approach from the social sciences. This paper aims to highlight applicants' languages on consumption and its implications to educational field, on account of consolidating the environmental education. It was assumed theoretically that different languages are anchored economically, socially referenced, politically detailed and culturally legitimized. The exposure is divided in four sections that highlight topics relevant to the genesis and current conduct circumstances in different languages of a consumer culture emerging in the midst of a society with persistent inequalities and impertinent socio-environmental degradation.

Keywords: Languages. Education. Environment. Contradictions. Social theory.

\section{INTRODUĈ̣̃O}

O presente texto se propõe o desafio de investigar linguagens, discursos, visões de mundo decorrentes de uma cultura de consumo e que implicam influências na construção das práticas educativas. A partir das ciências sociais, aborda diferentes linguagens presentes numa sociedade, que, por sua vez, incidem seja sobre as práticas escolares em particular, seja sobre o sistema de ensino e as práticas socioeducativas em geral. Portanto, a reflexão se insere na temática dos fundamentos para compreender as possibilidades e os obstáculos sociais ao campo da educação. Convém alertar para a complexidade no entrecruzamento de diferentes linguagens no campo da cultura de consumo, da educação na sociedade da informação e da instrumentalização da produção de conhecimentos.

Numa perspectiva cultural da linguagem ordinária do consumo, a partir de uma visão antropocêntrica, destacam-se a distinção, as diferenças, os problemas ambientais, a cidadania e a qualidade de vida. A ampliação das práticas de consumo engendra diferentes linguagens e significados socialmente atribuídos, também consiste num processo político de apropriação de informações, desafiando a disseminação de conhecimentos por meio da educação. Ao problematizar as questões ambientais, atentamos para os entrelaçamentos entre consumo e distinção social, entre público e privado, entre a cultura informada e a linguagem da educação. Parece usual olvidar a força das estratégias de 
consumo, os mecanismos de convencimento ou os apelos exteriores às mercadorias na formação e mudança de valores e práticas sociais.

As lentes do investigador, enquanto no campo de uma ciência social, exigem tanto a movimentação de técnicas de pesquisa quanto uma sistematização do conhecimento, desvendando relações veladas pela aparência dos fenômenos. Ao longo do texto, realizase um esforço intelectual para uma abordagem não normativa da realidade, mas aponta fundamentos das ciências sociais para elucidar as linguagens que incidem na educação em face da aderência à lógica do consumo ${ }^{1}$. Uma preocupação tanto quanto possível realista, colocando sob a mira da análise o imaginário de que, no contexto do consumo, é possível emergir uma linguagem para a educação, ou ainda uma leitura crítica com relação à publicidade. Neste sentido, usual na abordagem do campo da educação, o dever ser é entendido também como uma incerteza em face da capacidade de consumir, ao mesmo tempo, a possibilidade de compreender, de forma criativa, o conteúdo e os apelos da publicidade.

As ciências sociais podem fornecer instrumentos para analisar a cultura de consumo de um segmento social como um comportamento que mantém mistérios, somente perceptíveis para quem examina funções latentes. O olhar sobre a cultura do consumo observará outros elementos do espaço, além da circulação de mercadorias e de atribuição de sentidos aos bens, vez que existe uma complexidade de articulações entre consumidores e as respectivas mercadorias, entre a dimensão material e imaterial, com atribuições de diferentes significados por meio da linguagem amparada nas relações sociais ${ }^{2}$. A revisão da literatura sobre as diferentes linguagens engendradas pela cultura de consumo não pode se valer do que se consideram as fontes de produção do conhecimento no campo e por isso pode parecer ao leitor que se transita por várias fontes secundárias ou comentadores.

$\mathrm{O}$ artigo se divide em quatro partes em cujas dimensões, a partir da ótica das ciências sociais, destacam-se temáticas pertinentes à gênese e circunstâncias atuais da gestação de diferentes linguagens de uma cultura do consumo emergente: o cenário da emergência do tema da cultura do consumo, sem menosprezar as dimensões relevantes da produção de mercadorias, especialmente numa perspectiva em que se ratificam a distinção, ostentação, entretenimento, bem como desigualdades, exclusões e endividamento; o alargamento do consumo coaduna-se com a emergência de uma nova linguagem de proteção do consumidor, sobretudo a dimensão da institucionalização, bem como a dubiedade da expressão, interrogando-se se a proteção 
é prioritariamente para o cidadão ou para manter níveis de concorrência; a linguagem apropriada para tratar das mercadorias pela publicidade ou destas na sua aparência e materialidade para com o destinatário geram tensões para o consumidor pela ambiguidade em referência à cidadania e às desigualdades; a ampliação da satisfação de necessidades, como condição de qualidade de vida, introduz mudanças de linguagem no relacionamento entre homem e natureza, ao mesmo tempo em que se expandem as tensões entre ampliação do consumo e a segurança socioambiental.

\section{A CULTURA DE CONSUMO E A LINGUAGEM DA DISTINÇÃO}

A forma do consumo na sociedade ocidental tornou-se uma das questões-chave para compreender os processos sociais, especialmente da educação e da cultura. Tais processos possuem uma conotação individual e coletiva, complexa e multifacetada, cultural e econômica, são tanto impostos ou desagregadores quanto escolhidos ou inclusivos. A cultura de consumo pode ser abordada como um espaço de negociação, de formulação de diferentes linguagens, como um conjunto de rituais ou ainda como significados socialmente compartilhados, correspondendo à dimensão material e imaterial da vida cotidiana.

Primordial compreender que o estatuto do saber na sociedade pautada pelo consumo também se situa sob o repto de se subordinar à lógica da mercantilização de todas as coisas. Com a proliferação das informações pelos novos instrumentos da informática, o saber científico e acadêmico enfrenta a concorrência de outros tipos de discurso ou técnicas da linguagem, pois que emerge uma nova e sôfrega forma de consumo imaterial, especialmente com um inusitado alargamento do imaginário. Neste mesmo processo social, ocorre a ressignificação por meio de novos artifícios da linguagem de todas as coisas ou dimensões da vida, em particular pelas novas gerações.

As linguagens engendradas pelo consumo são socialmente construídas a partir das confluências e decorrências de práticas sociais que originam significados. Existe uma dialética na construção dos significados que caracterizam uma sociedade, um entrelaçamento entre a dimensão subjetiva na apropriação dos bens e os fatos objetivos das relações sociais. A linguagem do consumo suscita o movimento que Berger e Luckmann (1998) denominam de tipificação, institucionalização e socialização. O consumo, como um produto 
social ou uma cultura, está inserido numa dinâmica de permanência e de ruptura possibilitados pela ressignificação.

Alguns fenômenos tecnológicos da modernidade são basilares para a construção da reflexão sobre a cultura de consumo na contemporaneidade, ou esferas que ganham relativa autonomia: a proeminência atribuída ao indivíduo sobre a coletividade e como fundamento dos direitos, pois cada indivíduo constitui-se uma totalidade cabal de sentido, gerando a ideologia do individualismo; o Estado de direito onde supostamente cada indivíduo é sujeito de direitos e gerencia suas capacidades e posses de forma desvinculada da sociedade como um todo, configurando aspectos centrais do mundo social; a construção dos direitos de cidadania com um largo espectro, mesmo em nações com desigualdades persistentes, num paradoxo de igualdade e diferença (Lavalle, 2003); a relativa autonomia da economia em face das determinações políticas e éticas, bem como recentemente em relação aos territórios nacionais.

A sociedade segregada não se dilui com a ampliação do consumo, senão que se ratificam novos espaços de diferenciação ou a invenção de outras maneiras de distinção, razão pela qual a defesa da pluralidade e do direito às diferentes linguagens pode contrariar o intuito de promover a cidadania. Os elementos relevantes do percurso de construção da sociedade de consumo tanto aludem ao consumo sob a ótica da produção, quanto da explosão da cultura, mas que não podem ser tidas como óticas que se sucedem no tempo e no espaço. Ao longo do século XX, consolidam-se abordagens concomitantes no tempo - ora a teoria social enfatiza a conexão do consumo com a economia e a massificação ou indústria cultural (teoria crítica), ora a sociabilidade construtora de identidades, de escolhas ou a cultura da emancipação.

Alguns autores apontam os obstáculos para que a ascensão dos direitos à diferença se tornasse referência normativa para um consenso sobre diferentes linguagens que ordenam as relações sociais. Num contexto de conflitos, a expressão "do consenso ao dissenso" (Oliveira; Rizek, 2007, p. 7) parece uma expressão adequada para descrever as consequências em face dos conflitos pelo uso de diferentes linguagens, que ultrapassam reformas educacionais. A educação poderia apostar nos desdobramentos da cidadania ativa, capaz de confrontar-se com a pobreza política efetivamente vigente. A pobreza política antes há de ser combatida, mas não propriamente acomodada, como apregoa a publicidade e a prédica da felicidade pelo consumo. 
O percurso das teorias sociais alicerça a interrogação sobre as diferentes linguagens do consumo ao longo do tempo, descortinando a reconstrução de significados. As análises contemporâneas sob o viés da pós-modernidade, na medida em que operam uma discussão com o escopo das teorias sociológicas, permitem apresentar argumentos sobre a centralidade da economia e da cultura: os argumentos desse viés explicitam a impossibilidade de realização de algumas angústias, paradoxos ou projetos da modernidade, entre os quais a formalização de uma linguagem de comunicação universal. De fato, existem alguns fenômenos da modernidade ou da pós-modernidade conectados aos efeitos da ciência, do progresso, da tecnologia, do imperativo do individualismo, da cultura do consumo e das obstinadas desigualdades. Algumas características da cultura de consumo possuem raízes, porém poucas vezes destacadas, junto aos desdobramentos da livre concorrência na sociedade capitalista e a reconstituição de desigualdades.

A lógica da expansão do consumo a qualquer custo também está conectada à oposição competitiva entre corporações, sejam elas identificadas com as fronteiras nacionais ou de âmbito global, bem como ao suposto anacronismo de guerras que se sucederam ao longo de todo o século XX. Além disso, a atribuição de significado, socialmente partilhado, faz com que todo o consumo abarque também a dimensão cultural. As preferências individuais, dirá Slater (2002), são construídas como necessidades em face do imaginário, e em relação aos recursos ambientais disponíveis possuem uma natureza social.

Os desdobramentos com a expansão do consumo e a centralização das decisões na lógica do mercado (ou os monopólios) acabam ofuscando as condições do mercado livre, da concorrência e da iniciativa na criação cultural sobre as quais se baseia a noção de autonomia individual. O pensamento utilitarista e sua pedra de toque é a existência do indivíduo livre e soberano, não referenciado às classes sociais, aos esquemas de poder e aos condicionamentos históricos (Cattani e Diaz, 2005). Isso, de fato, é similar à proposição da emancipação por meio do processo educacional ou a liberdade de escolha em face dos bens de consumo. Assim, parece estar em curso a invenção da heteronomia, que se situa entre a individualização e a massificação. Combinam-se, portanto, características da sociedade atual como pós-industrial e pós-moderna, bem como pós-individualista e pós-coletivista. Ao mesmo tempo, o indivíduo, na perspectiva da emancipação, sucumbe ao consumo organizado sob o predomínio de monopólios, à publicização da intimidade ou à 
capitulação invasiva e interiorizada (Giddens, 2005), à ótica ditatorial das marcas no ramo da moda, ao império da estética dos corpos, à crise dos modelos cotidianos ou familiares substituídos pelo enfeitiçamento ou mito das celebridades, à permanente conexão com o mundo pelas novas tecnologias.

Ao mesmo tempo em que retine no debate acadêmico e político, com frequência, em meio à estima pela democracia, à saudação aos múltiplos direitos, à reflexão sobre consumo, igualmente ecoa, de forma meritória, o discurso sobre a queda das segmentações sociais ${ }^{3}$. Segregação social e discriminação cultural decorrem do ordenamento da apropriação desigual do espaço e dos bens naturais, prosseguindo no resguardo da cultura de consumo escorada em desigualdades. A ferida social e cultural pelos novos muros, os visíveis e os invisíveis, largamente abordados por Castells (2008), não é apenas um golpe nos anseios humanitários, porém uma profunda suspeita ante a universalização da cultura de consumo e desconfiança nos ideais da (pós) modernidade, estendendo a insegurança quanto ao destino da democracia e ao futuro de um convívio social intercultural.

\section{A LINGUAGEM DA PROTEÇÃO DO CONSUMIDOR: SEDUZIDO E DISTINGUIDO}

Demonstrar o intenso relacionamento entre as linguagens do lazer, cultura e consumo (Taschner, 2009) significa reconhecer que, na gênese do processo social do consumo, há uma associação reiterada com distinção social em conexão com economia, cultura e política. A construção do elo entre consumo e lazer se fortalece por meio do fenômeno da cultura de massas, em que, de alguma forma, o espaço para o consumo se alarga dentro do tempo reservado ao lazer, cuja perspectiva pertence ou caracteriza o século XX; todavia há o reconhecimento das diferenças culturais, bem como as desigualdades em relação tanto ao lazer quanto ao consumo. Considerando que vige um ingresso restrito à concretização do consumo, mesmo assim os empobrecidos também estão cingidos pela cultura de consumo, porém não alcançam um desempenho participativo efetivo ou o seu poder real de decisão é restringido (Bauman, 1998).

Para além das virtudes da cultura de consumo, talvez convenha destacar alguns paradoxos ainda em voga ou dos quais somente uma perspectiva crítica (Loureiro, 2004) pode dar conta de explicitá-los. Vejamos algum par imperfeito: o nexo entre tempo livre e capitalismo, entre lazer/prazer e consumo, entre igualdade de acesso ao consumo e equidade social, entre cidadania 
e shopping centers como catedrais de adoração das mercadorias. Um dos traços característicos da cultura de consumo na atualidade refere-se ao fenômeno da transformação do território de um shopping center como o lugar mais frequentado de uma cidade; para uns será um consumo material, para outros a satisfação do imaginário. A compreensão do consumo como cultura imaterial e material constitui, de fato, uma dinâmica e não somente uma oposição; assim se procura transcender a dualidade usual entre sujeitos e objetos, entre apropriação subjetiva e relações sociais (Miller, 2007). A menção remete a um olhar sobre as tensões geradas pelas novas tecnologias de comunicação, linguagens, mediações e até tendências alimentares. Neste ínterim, desperta a relevância de situar as contingências do sujeito nas controvérsias e circunstâncias na capacidade de conviver com a tensão entre a pertença a grupos e à história. "O sujeito é o movimento pelo qual buscamos nosso caminho em direção a nós mesmos em meio à desordem e à confusão das situações sociais, das ideologias e dos discursos" (Touraine, 2009, p. 168).

Os bens consumidos reforçam a compreensão do valor de troca e correspondem à definição de necessidades historicamente postas, em que qualidade de vida equivale ao usufruto da diferença. Negar o nexo entre consumo e meio ambiente, produção e cultura, entre entretenimento e endividamento como processos imbricados significa fragilizar-se para entender a complexidade, contradições e ambiguidades do presente (Ruscheinsky, 2009). A dinâmica da expressão da insatisfação corresponde a uma lógica da sociedade contemporânea onde o imaginário da premente satisfação das necessidades resume-se, acima de tudo, na lógica social da diferenciação.

A emergência socialmente reconhecida do consumidor, associada ao direito de proteção social, se dá na circunstância histórica em que se pode atribuir a característica do consumo à sociedade ou ao consumo em massa, cujo olhar imediato já não basta (Botto, 2008). A proteção ao consumidor busca, no espaço concorrencial, abolir, por força de lei, a concorrência desleal e assim informa que a satisfação do consumidor possui oposição e contestações. Em suma, a emergência do consumidor no espaço público implica um alargamento progressivo de áreas e mercadorias regulamentadas, o que, por sua vez, se dá em consonância com maior intervenção do Estado na economia.

Entre as contribuições principais de políticas nacionais da proteção do consumidor está o fato de servir de mecanismo suplementar para expandir as corporações, deter formas de concorrência e somar lucros, controlando a qualidade das mercadorias 
em circulação (Taschner, 2009; Botto, 2008). De fato, o código do consumidor não possui eficácia espraiada para outros setores sociais, pois há reconhecidamente uma produção de bens com qualidades distintas para usos numa sociedade desigual, bem como as populações em busca de proteção às culturas tradicionais, sendo inoperante em face da dependência e pobreza.

A abordagem da democratização do consumo enseja alguns paradoxos (Ruscheinsky; Calgaro; Augustin, 2010): o entrelaçamento progressivo entre entretenimento e consumo, com mudanças de visual e rompimento de barreiras entre consumidor e os respectivos bens, acirrando o processo de mercantilização; a democratização faz reinventar novas formas de distinção, pois pela própria dinamiza a difusão dos bens e lhes retira a capacidade distintiva e seu poder de sedução ao diferente; a ampliação do acesso aos bens socialmente produzidos convive com as desigualdades, pois a concentração do poder não se desmanchou por simpatia ao consumidor. Num contexto de desigualdades gritantes, em alguns segmentos sociais, o consumo de um item necessariamente ocorre em detrimento de outros.

$\mathrm{Na}$ lógica da cultura de consumo, existe uma confluência entre o emaranhado das novas tecnologias, a cultura pautada pelo individualismo, a geração continuada de riqueza concentrada e a depreciação dos bens ambientais. A degradação ambiental, até certo ponto, constitui uma consequência inevitável ou uma externalidade cujo ônus tende a ser transferido para toda a sociedade. O combate a uma cultura do desperdício por segmentos ambientalistas e ao consumo desigual na sociedade brasileira permanece focado em questões periféricas, como o efeito perverso dos combustíveis fósseis ou agroindustriais, ou o depósito adequado dos resíduos no espaço urbano, mas não atenta para as causas sociais dos respectivos problemas.

Observando-se o cenário, fica evidenciado que são frágeis os atores sociais que questionam radicalmente os efeitos perversos da forma desigual em que se mantém a cultura de consumo numa sociedade desigual. A parcialidade ou parcimônia no acesso ao consumo ${ }^{4}$, por ironia dos argumentos ambientalistas, se é profundamente injusta do ponto de vista social, poderia ser largamente desejável para equacionar o assédio desmedido aos bens naturais (Sato; Carvalho, 2005).

Os movimentos sociais explicitam, por meio de suas ações, os conflitos culturais e políticos, até mesmo a tensão entre valor de uso e valor de troca. Estes, em suas aporias, ilustram a capacidade de desenvolver uma autonomia em face ao poder constituído por conta da publicidade para o consumo e, ao mesmo tempo, a sua 
difusão como um ator no mercado, que busca formas de proteção (Botto, 2008). A cultura de consumo engendra protagonistas que entram em campo para o surgimento da sociedade de mercado ou para alargar os quesitos da sociedade de direitos.

Ao leitor atento chama a atenção que a proteção ao consumidor está atravessada por um discurso ambíguo: o centro da questão pode ser o consumidor ou o enquadramento da concorrência. Isto é, está posto o dilema entre medidas para delimitar a circulação de mercadorias e os direitos de cidadania. A inabilidade de gerenciar riscos e as incertezas fabricadas dentro das relações concorrenciais ou o descrédito ante as esperanças em soluções de mercado para os problemas dos consumidores faz emergir a legislação de proteção ao consumidor. As garantias em face dos produtos mostram a tendência de considerar incertezas e perdas do consumidor, ou uma tensão permanente entre o campo da produção e dos usos culturais, bem como as tensões contemporâneas entre público e privado (Dupas, 2003). O sistema de consumo requer, acima de tudo, um conjunto de informações por meio do qual se comunicam as qualidades dos produtos do mercado a ser consumidos. Decorre dessa circunstância a emergência da legislação sobre o campo do consumo: visa à regulação das relações de concorrência, bem como entre a produção e o consumo. Enfim, resulta na proteção do consumidor.

\section{A LINGUAGEM DAS MERCADORIAS E A TENSÃO DO CONSUMIDOR}

A idéia da diversidade de linguagens pode levar à revisão da representação da vida social e dos nexos entre as peculiaridades do consumo e a dimensão cultural. A mudança de paradigma na abordagem consiste em perceber os nexos entre a linguagem social sobre a vida coletiva e a linguagem cultural engendrada pela dimensão material (Touraine, 2006). Toda a práxis pode ser expressa por meio de linguagens e como tal abordamos a possibilidade de o consumo que perpassa as relações sociais ser expressão de diferentes linguagens. Nesse caso, a linguagem do consumo, da mesma forma que o consumo como linguagem ${ }^{5}$, em suas diferentes formas, atua como organizadora de relações sociais e de expressões de conflitos socioambientais.

É possível estabelecer nexos entre a cultura do consumo e a questão do enfeitiçamento, pois ambos remetem à emergência de um espaço social com imagens e símbolos acoplados socialmente aos bens de consumo e à conversão do valor de uso em valor de troca, para robustecer os atrativos da aparência e para difundir a 
crença de que estes são efetivamente qualidade de vida. Todavia, o consumo somente como armadilha aparece como a etapa derradeira do círculo da produção e circulação, pois a sina para o descarte é hoje socialmente reconhecida como o destino final dos bens e não a permanência sob a guarda dos consumidores. A posse de bens ou o trânsito destes pela vida cotidiana, diferenciado de acordo com os grupos sociais, está na emergência de diferentes linguagens a propósito de uma cultura de consumo.

O imaginário de gozo com a mercadoria ganha as peculiaridades do lugar social. A idéia de fetichismo das mercadorias ${ }^{6}$ vem do fato de serem revestidas de um caráter mítico ou tratadas como bens de consumo destinados prioritariamente à qualidade de vida: as mercadorias ocultam o esforço do trabalho e, na mesma medida, carregam consigo as relações sociais que se estabelecem no campo da produção (Castells, 2008); a compra com valor de troca torna os próprios consumidores intercambiáveis com as mercadorias, ou similares e volúveis como estas. A cultura de consumo também é uma forma de suavizar o processo da sociedade das mercadorias ou a instauração de um espaço mágico da troca de mercadorias em que tudo se converte em mercadoria.

Os avanços tecnológicos assumem a forma de constante metamorfose, própria do capitalismo em sua capacidade de reverter as oposições ou de inventar linguagens de legitimação ou de camuflar a persistência das desigualdades. Cabe suspeitar da naturalização de processos sociais, por isso, para Ramos-de-Oliveira (2001, p. 21), "comportamentos que encontravam protestos num período vão se instalando e adquirindo garras nos períodos seguintes. Tudo se revoluciona nos movimentos do capital. Tudo se torna simples mercadoria, pronta para consumo, mas destituída de traços realmente significativos."

O alargamento do consumo para outros ou todos os segmentos sociais pode ser de todo desejável para ampliar as condições de efetivação da cidadania, rompendo com a lógica das desigualdades e de gritantes diferenças (Lavalle, 2003). Todavia, a gestão responsável do ponto de vista ambiental questiona não somente a matriz do uso da energia, bem como entende que expandir o consumo, em termos de qualidade de vida, inexoravelmente atua sobre os atributos da água e do espaço, mas também questionar o consumo geral de energia.

A possibilidade distintiva dos bens diminui quanto mais cresce o número de consumidores, mas a dinâmica das desigualdades destaca novos bens para a sobrevida da distinção e a disparidade social 
é retida. Neste argumento, não há possibilidade de nexo significativo entre consumo e cidadania, a não ser por razões estritamente externas ao campo do consumo (Ruscheinsky; Calgaro; Augustin, 2010). Além do mais, a produção de resíduos em fartura representa o oposto da racionalização econômica, bem como um possível risco para os direitos de cidadania. A abundância do descartável, socialmente consolidada, convive com frágeis mecanismos para a resolução de problemas com o destino final, como o reuso ou a reciclagem.

As estratégias de políticas públicas ambientais centradas no consumo enchem de intrigas as interpretações das ciências sociais: compreendem uma forma de enfraquecimento dos atores sociais em sua ação política contemporânea; consiste na redução do cidadão à esfera de sua capacidade de consumo; expressa a gênese de uma cultura política emergente com nexo entre democracia, informação e meio ambiente (Barboza, 2008; Castells, 2008). As tensões permanecem sobre a ponderação das questões ambientais nas práticas sociais do consumo, se fortalecem ou se depreciam o ímpeto para com a cidadania, como ação política para efetivar direitos. A análise sociológica de Portilho (2005) aborda as contingências para a possível emergência de atores sociais em torno do consumo, bem como uma eventual centralidade das abordagens a partir do discurso em oposição ao consagrado campo da produção e do trabalho.

A ambiguidade acompanha a questão da cultura de consumo, porvezes em confronto, outras em fomento à cidadania, especialmente na medida em que se situa na lógica da igualdade e da diferença (Lavalle, 2003). Sob o olhar da crítica, a categoria de cidadão se diferencia da qualidade de consumidor, que, por sua vez, se restringe a todo indivíduo dotado de poder aquisitivo diante das mercadorias ofertadas. Movida pelo discurso mediático, vige no mercado uma concepção de que ser cidadão transmuta-se na condição de ser um consumidor e, como tal, a participação no consumo conduz à inserção social e política. Este fenômeno levou Canclini (1996) a cunhar a expressão "cidadãos do século XIX e consumidores do século XXI".

Tanto o nexo entre consumo e cidadania, quanto entre cultura e entretenimento são questionados pelo endividamento como um fenômeno social relevante. A cultura de consumo se forja igualmente na ampliação do acesso ao crédito, alargando comprometimentos com a sua lógica, de alguma forma na mesma medida em que tal prática implica uma forma de inclusão social. Numa sociedade insatisfeita, mas que busca suprir um imaginário de necessidades, os indivíduos sinalizam no consumo uma centralidade 
da vida, suposta fonte de realização de sonhos e de felicidade. $\mathrm{Na}$ cultura de consumo, os cidadãos compram como uma forma de lazer, em especial com a possibilidade de passear em meio às mercadorias, abrigado do sol, da chuva ou do frio.

A junção entre entretenimento e endividamento dilui fronteiras ou o contínuo ímpeto ao consumo no sentido compulsivo pode até gerar uma desestabilização financeira. O consumo como lazer, distinção social e endividamento pode afetar todos os segmentos sociais ou faixas de renda, pois que se trata de um fenômeno característico de uma sociedade em tempo de possibilidades ou saciedade ilimitada. Os apelos à população para que se arrisque consumindo é justificado como solução para uma sociedade em que o sistema produtivo e a circulação estão em crise, desqualificando, dessa forma, as armadilhas da irracionalidade deste empreendimento em decorrência da degradação de recursos naturais (Bosi, 2010).

A lógica social que sustenta a cultura de consumo relega a terça parte da América Latina a viver abaixo da linha de pobreza e permite que outro tanto sobreviva no horizonte da mera satisfação de necessidades básicas. A lógica capitalista requer a sobreposição da ideia da abundância sem igual e, ao mesmo tempo, a destruição permanentemente de bens para criar escassez, para cujo intuito a linguagem da publicidade exerce um papel preponderante. $\mathrm{Na}$ lógica da eficiência de uma nova cultura do consumo, torna-se igualmente relevante alimentar permanentemente a ideia da escassez acoplada à especificidade da multidão dos bens a ser absorvidos. Os bens de consumo podem ser naturalmente ineficazes para conseguir fornecer a satisfação almejada, tanto mais quanto o imaginário se sobrepõe à dimensão do valor de uso.

$\mathrm{Na}$ cultura de consumo de bens imateriais, também pode se verificar as consequências do excesso de sons e imagens, ou o sucumbir ao excesso de informação; mesmo com malabarismos, tal realidade vem mudando a visão de mundo e as práticas sociais, bem como influenciando a capacidade de concentração, a excitação e a criatividade. A situação inversa a este stress é o tédio proporcionado pelo silêncio, detestado por quem sucumbiu à linguagem sonora e informacional. A atração pela estimulação informacional pode beneficiar a aprendizagem, com mais eficiência para encontrar informações ou acuidade visual, mas tende a ser contraproducente ao valorar informações irrelevantes ou viciar-se em jogos eletrônicos.

A cultura caracterizada pelo binômio consumo e qualidade de vida possui uma desconexão ou um desencaixe com as causas 
enfocadas pela crise ambiental. Os dilemas apresentados junto ao nexo entre consumo e cidadania referem-se fundamentalmente à ausência de movimentos sociais para realizar mudanças radicais econômicas, sociais, políticas e ecológicas para situar em outro patamar o mesmo nexo. O cenário convive com múltiplas formas de reformismo ecológico ou de capitalismo verde que se constitui em práticas sociais ou proposições paliativas ante as causas profundas da crise ambiental.

\section{AS MUDANC̣AS DELINGUAGEM E AS TENSÕES ENTRE CONSUMO E SEGURANÇA}

A análise das mudanças do perfil das classes sociais brasileiras nos últimos anos refere-se à queda suave ou à redução da desigualdade de renda e possui, como consequência, uma influência sobre os padrões de consumo ou a ampliação do acesso aos bens industriais. O que era tido outrora como privilégio da classe média se espraia para praticamente toda a população, tendo como desdobramento a difusão e a adesão também a valores tais como a ambição de ascender socialmente, a aspiração a produtos de última geração tecnológica, valorização da escolaridade, reconhecimento do mérito e do desempenho individual.

Entre as principais mudanças ocorridas nos últimos anos, encontra-se uma aproximação de expectativas em termos de consumo de bens e de acesso aos serviços públicos. Ocorre também um sentido de desilusão ou desconfiança dos segmentos pobres nas organizações sociais ou de outra natureza que se dedicam ou prometem diminuir as desigualdades pela via coletiva. Neste setor, está em declínio a confiança que se restringe predominantemente aos familiares, poucos vizinhos ou amigos de trabalho ou lazer, bem como se estende a dependência de políticas sociais (Paugam, 2003; Castro et al., 2009). Este fenômeno explica os extensos e volumosos obstáculos para a formação e o prosseguimento de formatos associativos com os trabalhadores informais na área da reciclagem.

Além desses fatores mencionados, a violência, factual ou imaginária, está mudando o comportamento social de praticamente todos os segmentos sociais, inclusive na carruagem da defesa de direitos, seja a ampliação para uma agenda difusa, seja ao gozo da vida em conjugação perversa com a violência. De fato, existe uma onda de visibilização das vítimas de violência de diversos tipos, tendo como consequência desta vitimização o crescimento das formas de segurança privada. As reações à violência, real ou fictícia, implicam mudanças 
de comportamento e a inovação na linguagem dos relacionamentos: seletividade das saídas noturnas e das formas de lazer, proteção dos domicílios com alarmes, redes elétricas ou contratação de segurança privada. Algumas expressões podem provir do campo da ciência política como a ideia de construir um contrato social intergeracional ou um pacto de tolerância e de compromisso ético mútuo.

Diante da globalização, emergem novas linguagens com uma sociedade evidentemente assimétrica, com sacudidas recursivas de crises intermitentes e com a difusão de riscos e formas de insegurança social e ambiental (Castel, 2005). Os sentimentos de insegurança parecem transversais na medida em que se adentram por todos os segmentos sociais, mesmo em face das certezas tecnológicas. O homo timens na era das incertezas e dos riscos socioambientais sobrepõe-se ao homo economicus, com graus de insegurança existencial significativos apoderou-se do homo sapiens; isso devido a confortos com um estado de incertezas dos avanços tecnológicos, fugacidade das novas identidades ou futilidade do prazer consumista. Sob a lógica da cultura do consumo, ocorre também concomitantemente a nova hierarquização dos espaços sociais e a persistência das desigualdades ou uma cultura que ratifica a linguagem da invisibilização dos desiguais (Cattani e Diaz, 2005). Além disso, do ponto de vista do crescimento da insegurança em meio ao alargamento do consumo, existe uma particularidade: o adverso pode estar visível aos olhos, todavia o tremer de medo é também acompanhado de um reforço do papel de cegos ante o desastre ambiental em curso.

Depois de transformar a questão ambiental em tema transversal, interdisciplinar e obrigatório no processo de educação de todo cidadão, ainda falta traduzir uma cultura política que compreenda problemas multicêntricos (Sato; Carvalho, 2005). Considerando a criatividade e o desenvolvimento de competências, a curiosidade exerce um papel importante ante uma realidade gestora de múltiplas respostas. O desencaixe ou a desadaptação criativa expressa as condições para gerar um contexto de mudanças ensejadas em relação à construção de novas perguntas para obter novas respostas ante uma necessidade de mudança nos hábitos de consumo para contornar o esgotamento de recursos naturais.

As considerações críticas feitas pelas ciências sociais dão conta da insuficiência de mapear a realidade objetiva mediante dados estatísticos que tendem a imobilizar o rosto do processo social. De acordo com o entrelaçamento entre consumo e desigualdades (Ruscheinsky; Calgaro; Augustin, 2010) e pela sua contribuição relevante, o estudo sociológico da linguagem permite detectar 
desigualdades invisíveis e algumas tendências de comportamento no interior das classes sociais.

A perplexidade atual se amplia com a propagação maciça das tecnologias de difusão das ciências especialmente mediante os recursos da informática. Diante dessa linguagem, parece sensato refletir sobre as motivações dos usuários, os efeitos em termos de fins, a prioridade sobre a iniciativa individual, ou a possibilidade de alterar patamares de exclusão ou de subordinação. Porto (2006, p.46) afirma que "as tecnologias põem à disposição do usuário amplo conjunto de informações/conhecimentos/linguagens em tempos velozes e com potencialidades incalculáveis, disponibilizando, a cada um que com elas se relacione, diferentes possibilidades e ritmos de ação”. A busca de informações que respondam às dúvidas dos indivíduos com o grau de escolha permitido pode ser um antídoto em relação a informações manipuladas pelo poder do mercado e pode desmontar tramas seculares da ideologia de dominação (Bosi, 2010). A linguagem da informática é moeda ambígua na medida em que interesses egocêntricos, perversos ou agressivos podem gerar situações inéditas de perversidade ou correntes ideológicas antidemocráticas, desde o consumo irresponsável, a idolatria do capital até o fundamentalismo.

Com os novos canais e as novas linguagens, parece que o conhecimento se resume em uma quantidade de informações e suas linguagens específicas ou códigos de interpretação. A transição ou deslocamentos dos conhecimentos sofrem os efeitos da miniaturização e disseminação de equipamentos informacionais, que aceleram a circulação do conhecimento e de mercadorias mediante os avanços na transmissão e transporte de sons e imagens.

Os mecanismos de participação política se fragilizam onde o poder de decisão centra-se no poder de compra. As dinâmicas da sedução, adesão, imaginário, indução e repressão simbólica são afirmadas por Bauman: “... mais amplo e mais profundo é o hiato entre os que desejam e os que podem satisfazer os seus desejos, ou entre os que foram seduzidos e passam a agir do modo como essa condição os leva a agir e os que foram seduzidos, mas se mostram impossibilitados de agir do modo como se espera agirem os seduzidos." (Bauman, 1998, p. 55). Para além da sedução que possui uma tendência universal, há que se considerar que, numa sociedade desigual, os setores sociais que não podem agir em conformidade com os desejos induzidos, mas o seu imaginário é regalado com o deslumbrante espetáculo da felicidade mercadológica. O consumo é 
a linguagem que demarca a via da qualidade de vida e do sucesso acoplado a possuir determinados objetos.

Considera-se que a educação pública brasileira se ocupa, em seu contingente predominante, do ponto de vista quantitativo, dos seduzidos e ao mesmo tempo frustrados ou reprimidos que possuem suas vidas relacionadas de alguma forma inversa à sociedade de consumo. A ambiguidade perpassa a busca da inclusão social, seja ao mercado de trabalho, seja ao acesso aos bens de consumo, na medida em que a educação pretende impulsionar uma crítica à sociedade excludente (Demo, 2009). Em se tratando da ótica de alimentar o imaginário do consumidor, as mensagens tendem a ser convincentes ou informação emotiva, ao mesmo tempo de fácil decodificação, especialmente na medida em que a linguagem visual se destaca e o consumidor tem acesso direto à manipulação das mercadorias.

\section{CONSIDERACְ̃̃ES FINAIS}

$\mathrm{Na}$ atual sociedade, o sistema educacional é apenas uma das agências de informação e de reprodução/criação em face de diferentes linguagens, bem como crescentemente permeada pela transversalidade e interdisciplinaridade. O quadro se torna mais complexo quando inserido numa sociedade da informação, administrada, consumista, saturada de informações profusas, fragmentadas e desconexas. A difusão do acesso à mídia e da informática consubstancia um impacto no sistema educacional, com o declínio da ênfase e preocupação com conteúdo e volume de informações, para tratar da linguagem de como acessar e organizar as múltiplas informações disponibilizadas.

A inovação nos significados do consumo, pela via dos novos produtos do desejo, transforma as formas da interação social, bem como vem incidindo nas atribuições da organização política para a democracia. Ainda mais, põe em nova escala a busca por uma ética de convivência, a persistência das desigualdades, os desafios e a articulação tanto das investigações ambientais quanto do conhecimento para superar a degradação da natureza e das relações sociais. O consumo introduz novas linguagens que transformam a compreensão do espaço e de suas formas de apropriação, o que ainda não significa uma articulação dos atores sociais para a superação das desigualdades de acesso ao consumo e aos direitos largamente definidos.

A educação se defronta com os problemas de tradução e de compatibilidade em face das linguagens computacionais, tanto quanto das linguagens em face de anseio generalizado de consumo. 
Pelas mudanças em curso, a natureza do saber se submete a novas linguagens, novos canais e torna-se operacional ou informacional. Seja com a expansão dos meios de comunicação ou da informação, seja com as novas linguagens atinentes ao consumo, verifica-se uma mudança do estatuto do saber e da transmissão de conhecimentos. As particularidades do consumo ou a expansão de suas fronteiras propiciam a um fenômeno em que se pode considerar o saber ou o manuseio de informações como mercadoria.

Os indivíduos utilizam a linguagem para relacionarem-se uns aos outros, usam-na para referir-se aos objetos do dia a dia, mesmo que seja o desejo de possuí-los, bem como as coisas representam uma linguagem em face da influência sobre os indivíduos. A grande maioria dos meus alunos de graduação se espanta com a simples observação não antropocêntrica, ou seja, sobre o intercâmbio imprescindível com a natureza: cada qual possui um conjunto de bens e ao mesmo tempo é possuído pelos respectivos bens. Todavia, esta dupla posse está circunscrita pela linguagem do consumo efêmero e da dinâmica do descartável.

Entre educadores ambientais tende a ser usual referir-se a práticas de consumo consciente como medida para debelar parcela importante da crise ambiental e social. Todavia, acima de tudo, paira a incerteza na definição ou delimitação do que sejam efetivamente os patamares de tal consumo, considerando que a definição de necessidades altera-se de acordo com o posicionamento de classe social.

Ao término do texto ousamos enfatizar que a abordagem tentou compreender que as diferentes linguagens correspondem a circunstâncias históricas datadas e, como tal, possuem uma autonomia relativa dos respectivos contextos. Alguns elementos destacados permitem referir que as diferentes linguagens representam um construto economicamente escorado, socialmente referenciado, politicamente circunstanciado, culturalmente legitimado.

\section{REFERÊNCIAS}

BARBOZA F., Rubem. As linguagens da democracia. Rev. bras. Ciências Sociais. 2008, v. 23, n. 67, p.15-37.

BAUMAN, Zigmunt. O mal-estar da pós-modernidade. Rio de Janeiro, Zahar. 1998.

BERGER, Peter L.; LUCKMANN, Thomas. A construção social da realidade: tratado de sociologia do conhecimento. 16. ed. Petrópolis: Vozes, 1998.

BOSI, Alfredo. Ideologia e contraideologia. São Paulo: Companhia das Letras. 2010. 424 p. 
BOTTO, Andrea. Quién defiende a los consumidores? Buenos Aires: Prometeo Libros, 2008.

CANCLINI, Néstor García. Consumidores e cidadãos - conflitos multi-culturais da globalização. Rio de Janeiro, UFRJ, 1996.

CARVALHO, Isabel C.M.; STEIL, Carlos A. O habitus ecológico e a educação de percepção: fundamentos antropológicos para a educação ambiental. Educação \& Realidade, UFRGS, v, 34, n 3, 2009, p. 81-94

CASTEL, Robert. A insegurança social: o que é ser protegido. Petrópolis: Vozes, 2005.

CASTELLS, Manuel. O poder da identidade. 6. ed. Rio de Janeiro: Paz e Terra 2008. p 141-168 CASTRO, Jorge A.; AQUINO, Luseni M. C.; ANDRADE, Carla C. (org). Juventude e políticas sociais no Brasil. Brasília: Ipea, 2009. http://www.ipea.gov.br/sites/000/2/livros/Livro_ JuventudePoliticas.pdf

CATTANI, Antonio; DÍAZ, Laura M. (orgs.). Desigualdades na América Latina; novas perspectivas analíticas. Porto Alegre: Ed. da UFRGS, 2005.

CAROSIO, Alba. El consumo en la encrucijada ética. Utopia y Praxis Latinoamericana, v.13, n.41, 2008, p.13-45. http://www.scielo.org.ve/pdf/upl/v13n41/art02.pdf

DELORS, Jaques. Educação: um tesouro a descobrir. São Paulo: Cortez/UNESCO/MEC, 2004.

DEMO, Pedro. Educação hoje: "novas" tecnologias, pressões e oportunidades. São Paulo: Atlas, 2009.

DUPAS, Gilberto. Tensões contemporâneas entre o público e o privado. São Paulo: Paz e Terra, 2003.

GIDDENS, Anthony. Sociologia. 4. ed. Porto Alegre: ARTMED, 2005.

GUIMARÃES, Gláucia; BARRETO, Raquel G. Linguagens na TV. Educação em Revista, 2008, n.47, p.41-54.

HELLER, Agnes. A sociologia como desfetichização da modernidade. Novos Estudos Cebrap, n. 30, 1991, p. 204-214.

KLIKSBERG, Bernardo. América Latina: La región más desigual de todas. Revista de Ciencias Sociales, v.11, n.3, 2005, p. 411-421.

LAVALLE, Adrián Gurza. Cidadania, igualdade e diferença. Lua Nova, São Paulo, CEDEC, n. 59, 2003, p. 75-93.

LOUREIRO, Carlos F.B. Trajetórias e fundamentos da educação ambiental. São Paulo: Cortez, 2004.

MILLER, Daniel. Consumo como cultura material. Horizontes Antropológicos. v. 13, n. 28,Porto Alegre, 2007, p. 30-43.

MACHADO, Monica; MARTINELLI, Fernanda; PINHEIRO; Marta. Publicidade para causas sociais: apontamentos sobre a experiência do laboratório universitário de publicidade aplicada (LUPA). Revista Signos do Consumo, v.3/1, 2011, p.57-74.

OLIVEIRA, Francisco; RIZEK, Cibele S. (org). A era da indeterminação. São Paulo: Boitempo, 2007

PAIVA, Ângela; BURGOS, Marcelo B. (org). A escola e a favela. Rio de Janeiro: PUC-RJ e Pallas Ed., 2010.

PAUGAM, Serge. Desqualificação social: ensaio sobre a nova pobreza. São Paulo: EDUC/ Cortez, 2003.

PORTILHO, Fátima. Sustentabilidade ambiental, consumo e cidadania. São Paulo: Cortez, 2005.

PORTO, Tania M. E. As tecnologias de comunicação e informação na escola: relações possíveis, relações construídas. Rev. Bras. Educação. 2006, v. 11, n. 31, p.43-57 
PROGRAMA DAS NAÇÕES UNIDAS PARA O MEIO AMBIENTE (Pnuma). Impactos ambientais do consumo e da produção: produtos e materiais prioritários. Bruxelas, 2010. http:// www.envolverde.com.br/\#

RAMOS-DE-OLIVEIRA, Newton. Do ato de ensinar numa sociedade administrada. Cadernos CEDES, v. 21, n. 54, Campinas, 2001, pp. 19-27.

RUSCHEINSKY, Aloísio. Desigualdades, meio ambiente e as mediações sociopolíticas. IN: MOLON, S.I.;e DIAS, C.M.S. (org). Alfabetização e educação ambiental: contextos e sujeitos em questão. Rio Grande: Ed. Furg, 2009.

RUSCHEINSKY, A.; CALGARO, C.; AUGUSTIN, R.L. Análise sociológica das desigualdades e os entrelaçamentos entre consumo e seus reflexos socioambientais. In: PEREIRA, A.O.K.; HORN, L.F. (org). Relações de consumo: consumismo. Caxias do Sul: EdUCS, 2010, p. 175-206.

SANTOS, Acácia A. A.; BOULHOCA SUEHIRO, Adriana C. y VENDEMIATTOO, Bianca C. Inteligencia y comprensión en lectura de adolescentes en situación de riesgo social. Paradigma, v. 30, n.2, 2009, p.113-124.

SATO, Michele; CARVALHO, Isabel (Org.). Educação ambiental: pesquisa e desafios. Porto Alegre: Artmed, 2005.

SLATER, Don. Cultura do consumo \& modernidade. São Paulo: Nobel, 2002.

SOARES, Magda. Linguagem e escola. Uma perspectiva social. São Paulo: Ática, 1989.

SPINK, Mary J. (Org.). Práticas discursivas e produção dos sentidos no cotidiano: aproximações teóricas e metodológicas. 3. ed. São Paulo: Cortez, 2004.

TASCHNER, Gisela. Cultura, consumo e cidadania. Bauru: Edusc, 2009, 189 p.

TILLY, Charles. O acesso desigual ao conhecimento científico. Tempo social, 2006, v. 18, n. 2, p.47-63.

TOURAINE, Alain. Um novo paradigma: para compreender o mundo de hoje. Petrópolis: Vozes, 2006. 261 p.

TOURAINE, Alain. Pensar outramente. Petrópolis: Vozes, 2009.

\section{NOTAS}

${ }^{1}$ Um exemplo similar, mas em outra versão teórica, com nítida proximidade com a antropologia, encontramos em Carvalho; Steil (2009), cuja reflexão ousa fazer o percurso do conceito de campo como abordagem das ciências sociais para oferecer sustentação à educação ambiental.

${ }^{2}$ A abordagem levada a efeito sobre a emergência e o significado social das linguagens reconhece a larga discussão na psicologia social (Spink, 2004), bem como a relevância da linguística em seus distintos matizes, todavia a ênfase recai sobre uma sociologia do cotidiano ou do conhecimento.

${ }^{3}$ Poderíamos dizer que a sociedade ocidental, num momento de expansão do bem-estar proporcionado pelo consumo, se surpreendeu com o nazismo, com o muro de Berlim, com a persistência dos efeitos racistas e da discriminação étnica em diversas nações. Todavia, usualmente são omitidos outros fenômenos, por vezes similares à queda do famigerado muro de Berlim com o fim do socialismo real; por isso, convém mencionar novos muros para nossa memória: entre israelenses e palestinos, entre americanos e mexicanos, em favelas cariocas, em várias situações na África e na Europa, especialmente contra imigrantes. 
${ }^{4}$ Mais do que a reprodução do capital, são as pressões do consumo por carne que são imprescindíveis para não conter o desmatamento causado pela pecuária na Amazônia; em face dessas circunstâncias, parece secundária a prática dos consumidores de obter as informações para se certificarem a respeito da origem dos produtos. A possível mudança quanto ao tipo de consumo possui algum significado de sucesso, em qualquer espaço urbano e em conexão como os mais diferentes problemas, na medida da sua junção com associações de defesa ao consumidor, entidades da sociedade civil e instituições ligadas à proteção do meio ambiente. O comportamento dos consumidores possui o poder de diluir o desmatamento da Amazônia, conquanto aliado ao poder da autoridade pública, constituída com poder normativo e de fiscalização. Por outro lado, a declaração da ilegalidade da pecuária da região amazônica tem a serventia de relacionar tal atividade a problemas como desmatamento, desertificação, trabalho escravo, emissão de gases e lavagem de dinheiro.

${ }^{5}$ Sobre esta abordagem afirmam Machado, Martinelli e Pinheiro (2011, p. 63) “O consumo, dessa forma, é coletivamente compartilhado de modo que as pessoas, além de receberem ou incorporarem os significados veiculados pelo discurso publicitário, nas interações sociais também constroem e atribuem, elas mesmas, significados aos bens. Os objetos passam então a funcionar como comunicadores e isso permite uma abordagem do consumo como linguagem e sistema de comunicação. Além dos objetos materiais, as trocas envolvem conteúdos e promovem interlocução entre as pessoas, de modo que os bens fazem parte de um sistema de informação e estabelecem relações sociais."

6 Cabe esclarecer que o "fetiche da mercadoria" é um conceito de matiz nitidamente demarcado, cuja raiz sabidamente origina-se do pensamento marxiano. Todavia, esta não é a ótica em discussão aqui. A característica fundamental consiste no enfeitiçamento das mercadorias que ganham tal grau de objetividade ou autonomia que os indivíduos fantasiam relações "humanas" com elas; ou mais ainda, ocorre um processo de reificação das relações sociais, ou seja, os objetos da circulação funcionam como mediação entre os indivíduos e grupos sociais. Aqui a discussão está na emergência das diferentes linguagens propiciadas pela lógica do consumo, pois que a sociologia é um instrumental apropriado para a desfetichização das relações do cotidiano (Heller, 1991).

Recebido: $25 / 08 / 2013$

Aprovado: 31/05/2014

Contato:

Universidade do Vale do Rio dos Sinos

Centro de Ciências Humanas

Av Unisinos 950 - Bairro Cristo Rei, São Leopoldo | RS | Brasil

CEP 93.022-900 